\title{
Outcomes of an aquifer assessment on the M1B aquifer ahead of Loy Yang Mine and considerations for future dewatering/depressurisation
}

\author{
R Turnbull GHD Pty Ltd, Australia \\ G Foley GHD Pty Ltd, Australia \\ J Missen AGL Loy Yang Pty Ltd, Australia
}

\begin{abstract}
AGL Loy Yang Mine is a brown coal (lignite) mine owned and operated by AGL to supply coal to its adjoining Loy Yang A power station and the neighbouring Alinta Loy Yang B power station for electricity generation. The open cut mine is located south of Traralgon, in the Latrobe Valley region of Gippsland, in eastern Victoria. Brown coal is mined using bucket wheel excavators and conveyors, from thick coal seams interbedded with sedimentary silt/clay layers. To date. groundwater extraction has occurred from confined aquifers of the Morwell and Traralgon Formations beneath the mine to mitigate floor heave by maintaining groundwater pressures below defined trigger levels as no significant aquifers have been exposed in the batters requiring dewatering. Geological modelling indicates that a sand interseam within the upper Morwell Formation, identified as the M1B aquifer, significantly thickens ahead of the mine to become a high yielding, regionally extensive aquifer of up to $20 \mathrm{~m}$ thickness.
\end{abstract}

Future mining operations, which have been planned until the mine's forecasted closure date of 2048, will expose this aquifer at various thicknesses within the mine's batters and floor from 2024 onwards, with potential for significant seepage. The presence of the aquifer therefore presents a number of challenges to future mining operations, particularly in relation to depressurisation, dewatering and slope stability. In particular, recent proposed changes in the rate and direction of mine expansion have expedited the need to investigate operational impacts posed by this aquifer. This paper details the findings of recent pumping test investigations undertaken on the M1B aquifer which have shown that the aquifer is regionally confined, has a high transmissivity and is hydraulically well-connected across the proposed future mine footprint. The groundwater chemistry is of low salinity, with slightly acidic $\mathrm{pH}$ and temperature around $40^{\circ} \mathrm{C}$, and various management options including surface water discharge are being assessed. The target aquifer's remoteness from the current mine footprint and associated dewatering infrastructure also presents logistical challenges regarding electricity supply and discharge options. The pumping test results are being used to refine the existing mine groundwater model to confirm the location and number of future M1B aquifer dewatering pump bores, with the ultimate purpose of reducing groundwater seepage and aquifer pressures to reduce risk of batter instability. In the longer term, the geological and hydrogeological modelling will assist in the detailed design of the permanent batters, mine grades and placement of overburden within the mine taking into consideration mine closure and rehabilitation options.

Keywords: Loy Yang, brown coal, aquifer, depressurisation, pumping test

\section{$1 \quad$ Introduction}

This paper details emerging depressurisation requirements for an approximately $150 \mathrm{~m}$ deep sand aquifer located ahead of the Loy Yang open cut brown coal mine, located south of Traralgon, within the Latrobe Valley region of Victoria. The relevant layer of the Morwell Formation, identified as the M1B aquifer, has to date been of minimal significance to Loy Yang mining operations due to its limited thickness, clayey lithology 
and low groundwater yield. However, geological modelling data indicates that this aquifer thickens to the east of the current mine, and therefore its potential impact on mining operations needs to be managed.

A number of investigations have been completed by GHD in recent years to characterise the lithological variation of the M1B aquifer and its hydraulic properties so that it can be appropriately incorporated into long-term mine planning and numerical groundwater modelling. Recent proposed iterations of the future 2048 mine plan, however, incorporate a mine development towards the southeast and this has necessitated a reassessment of $\mathrm{M} 1 \mathrm{~B}$ aquifer dewatering/depressurisation requirements including bore locations and timing of commissioning.

To assist in the groundwater modelling of the revised M1B aquifer dewatering requirement, characterisation of the aquifer parameters and extent of the M1B aquifer ahead of the current mine is required. Loy Yang's first M1B aquifer pump bore, LY4997, was drilled and installed in October 2018, approximately $750 \mathrm{~m}$ east of the current mine footprint within a targeted thick sequence of the aquifer. A seven day constant rate pumping test of this bore was completed in April 2019 to determine the M1B aquifer hydraulic properties for inclusion in the groundwater model. This paper details the outcomes of this pumping test assessment and future depressurisation considerations.

\section{Aquifer characterisation}

Latrobe Valley geology broadly comprises gently folded Eocene to Miocene-aged swamp and alluvial deposits unconformably overlying Mesozoic sandstone basement of the Strzelecki Group. The deposits are characterised by thick lignite seams (often $>100 \mathrm{~m}$ thick) interbedded with thinner sediment (interseam) layers (GHD Group Pty Ltd 2015). Figure 1 demonstrates a 2D cross-section (west to east) of the Loy Yang mine, and stratigraphic units ahead of the mine (east). The location plan of this cross-section is provided as Figure 2.

The M1B aquifer is comprised primarily of quartz sand, with grain size increasing (and clay/silt content decreasing) towards the east (which is also the direction of mine advancement). Lithology within M1B aquifer pump bore LY4997 was recorded as a 'medium to coarse quartz sand' with an absence of clay/silt. Geological modelling shows the M1B aquifer thickness within the study area (i.e. east of the current mine footprint), thickens considerably from approximately $3 \mathrm{~m}$ at the current eastern extent of the mine, to greater than $15 \mathrm{~m}$ in the northeast corner of the future mine footprint. The aquifer also dips away from the advancing mine, as shown in Figure 3, which is an isometric cross-section of the operational mine face and stratigraphic units ahead of the mine. The M1B aquifer depth in the study area is approximately 160 to $170 \mathrm{~m}$ below surface. The thick overlying/underlying coal and clay units are interpreted to act as aquitards, and the aquifer is therefore considered to be confined.

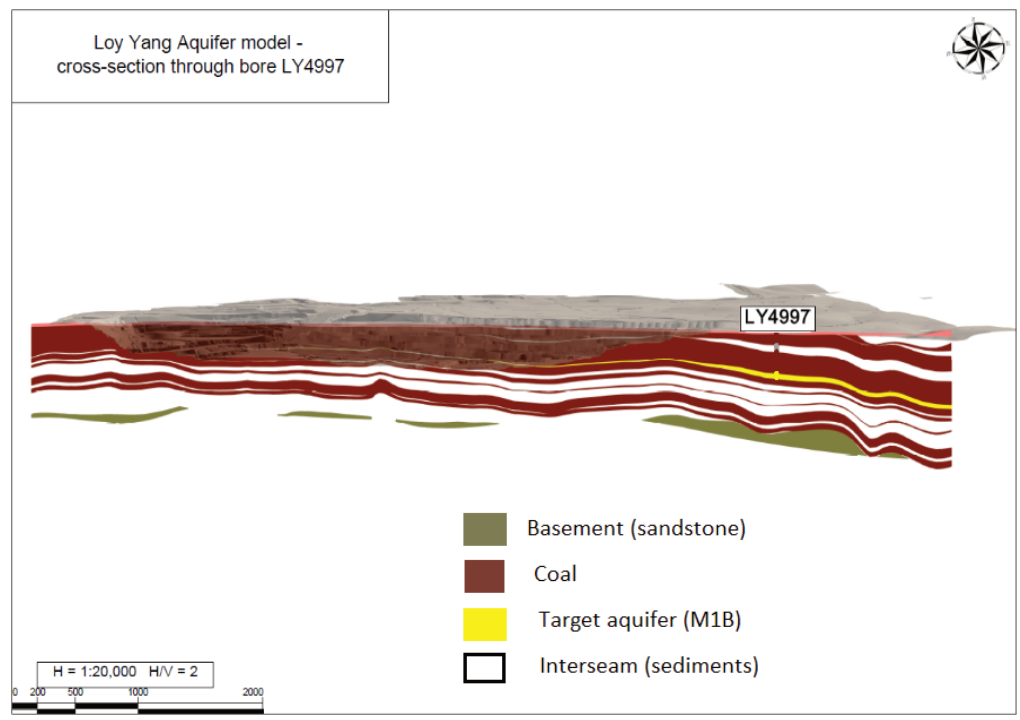

Figure 1 Cross-section (W-E) showing current pit outline and M1B aquifer, and location of bore LY4997. Source: Minescape Loy Yang Aquifer Model 


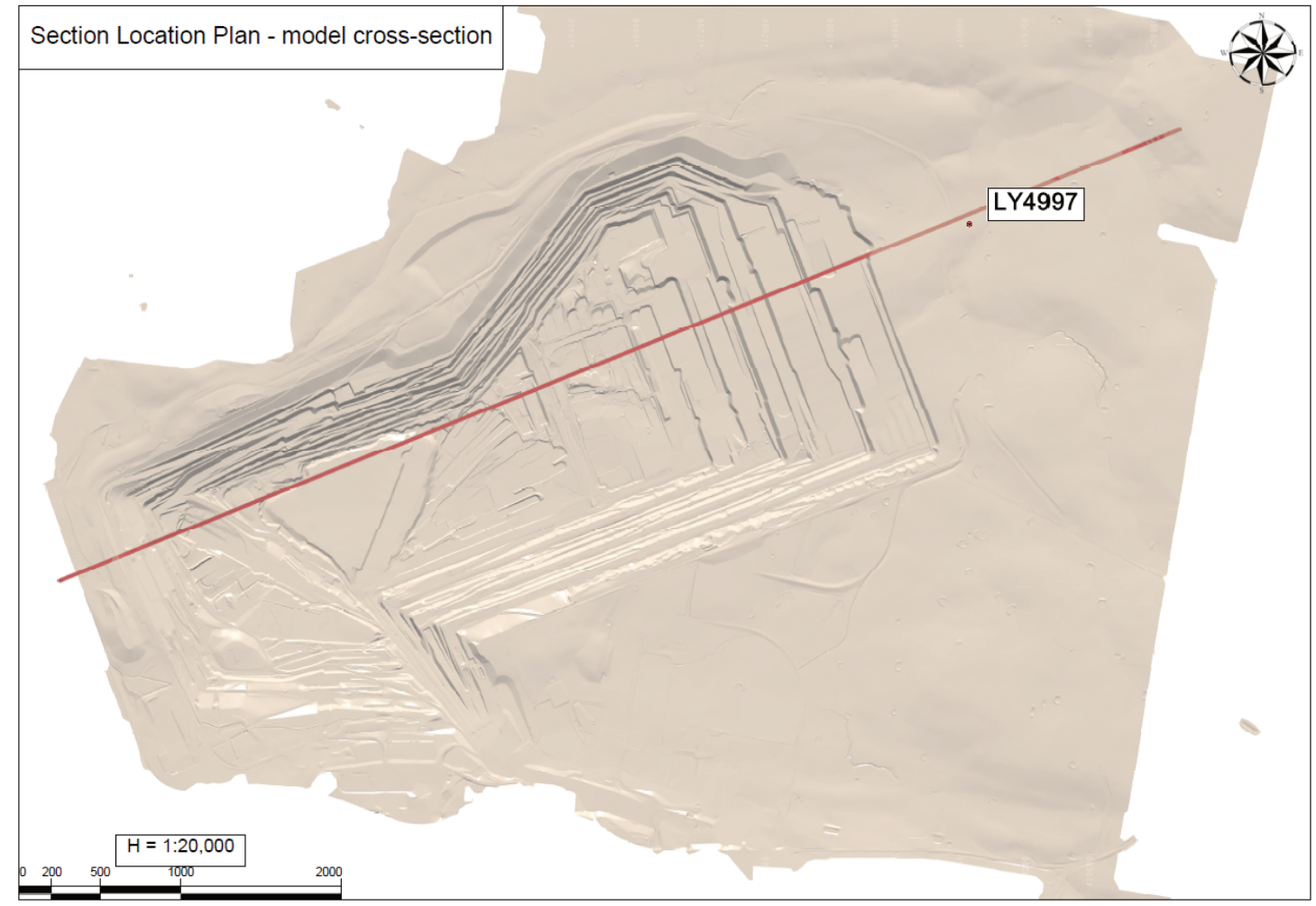

Figure 2 Cross-section location plan relative to Loy Yang mine and bore LY4997

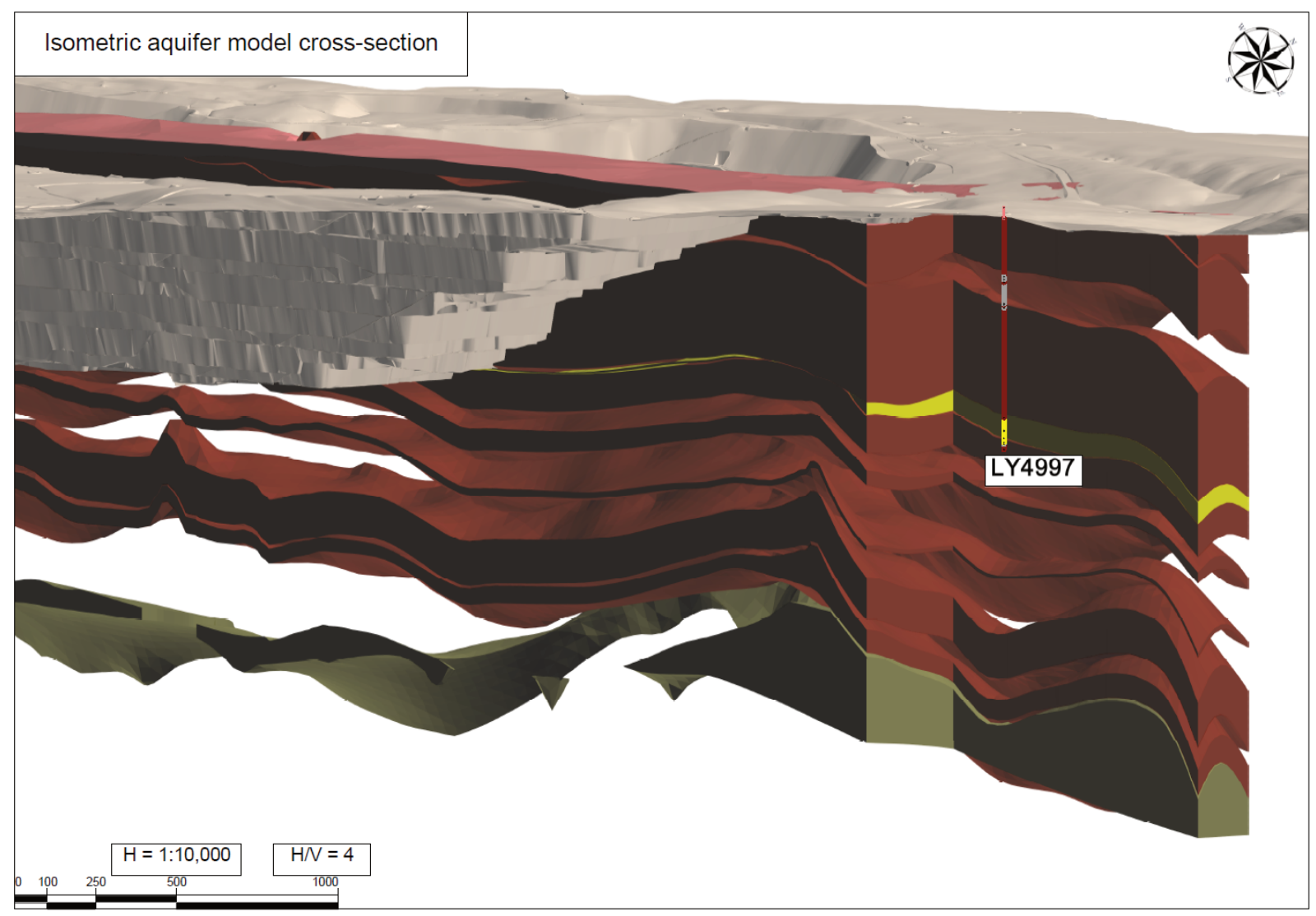

Figure 3 Isometric cross-section of mine, stratigraphic units ahead of mine and bore LY4997. Source: Minescape Loy Yang Aquifer Model 


\section{$3 \quad$ Pumping test methodology}

Loy Yang's first M1B aquifer pump bore, LY4997, was installed with $300 \mathrm{~mm}$ fibre-reinforced plastic (FRP) casing, and a $12 \mathrm{~m}$ stainless steel screen located between 165 and $177 \mathrm{~m}$ depth. The bore was developed via airlifting with a natural 'gravel pack' and a groundwater sample was taken at the end of bore development in 2018. Pumping tests were conducted for AGL Loy Yang by Agmek Ballarat Pty Ltd using an electronic submersible pump with a variable speed drive controller and a flow meter, powered by a diesel generator. As outlined in Table 1, the first day of the pumping test program consisted of step tests which involved pumping rates of 20, 25 and $30 \mathrm{~L} / \mathrm{s}$ on 9 April 2019. Based on the results of the step testing, a flow rate of $30 \mathrm{~L} / \mathrm{s}$ was selected for the constant rate test, which was also the maximum flow capacity of the installed test pump.

Table 1 Pumping test rates and details

\begin{tabular}{lllllll}
\hline Test & Phase & Start time & Finish time & $\begin{array}{l}\text { Duration } \\
\text { (mins) }\end{array}$ & $\begin{array}{l}\text { Flow rate } \\
(\text { L/s })\end{array}$ & $\begin{array}{l}\text { Drawdown } \\
(\mathbf{m})\end{array}$ \\
\hline Step & Step 1 & $09 / 0411: 15$ & $09 / 0412: 15$ & 60 & 20 & 4.6 \\
& Step 2 & $09 / 0412: 15$ & $09 / 0413: 15$ & 60 & 25 & 6.7 \\
& Step 3 & $09 / 0413: 15$ & $09 / 0415: 15$ & 120 & 30 & 7.5 \\
& Recovery & $09 / 0415: 15$ & $10 / 0410: 00$ & 1,125 & - & - \\
\multirow{2}{*}{$\begin{array}{l}\text { Constant } \\
\text { rate }\end{array}$} & Pumping & $10 / 0410: 00$ & $17 / 0410: 05$ & 10,080 & 30 & 11.2 \\
\hline
\end{tabular}

Note: drawdown was below original static water level (SWL = approximately $41.5 \mathrm{~m}$ below top of casing)

Seven surrounding observation bores were monitored at regular intervals for water levels during the pumping test, with distances varying from 14 to $829 \mathrm{~m}$ from the pumping bore. Monitoring bores comprised of a combination of vibrating wire piezometers (VWPs) and PVC screen standpipes. The distribution of these bores relative to LY4997 (pumping bore) and the Loy Yang mine is shown in Figure 4.

Water quality readings (temperature, conductivity, $\mathrm{pH}$, redox and dissolved oxygen) were taken at the point of discharge on a daily basis using a calibrated water quality meter, and samples were collected on 15 April 2019 from a tap connected to the bore headworks for laboratory analysis. The sample was analysed for a selection of parameters including nutrients, basic water chemistry parameters and metals. The purpose of this was to characterise the groundwater type and quality, which may assist in understanding water management options in future, including treatment and disposal requirements. 







\section{$4 \quad$ Results}

\subsection{Drawdown responses}

Maximum drawdown responses from the pumping and monitoring bore network at the end of the constant rate test are summarised in Table 2. As shown by this data, with the exception of LY5061, extent of drawdown generally increased with increasing distance from the pumping bore (from a maximum of $7.1 \mathrm{~m}$, to a minimum of $3.6 \mathrm{~m}$ lowering of groundwater elevation).

Table 2 Summary of constant rate test drawdown

\begin{tabular}{lllll}
\hline Bore & $\begin{array}{l}\text { Radial distance }(\mathbf{m}) \\
\text { from bore LY4997 }\end{array}$ & $\begin{array}{l}\text { Aquifer thickness } \\
(\mathbf{m})\end{array}$ & $\begin{array}{l}\text { Initial RWL } \\
(\mathbf{m} \text { AHD) }\end{array}$ & $\begin{array}{l}\text { Drawdown } \\
(\mathrm{m})\end{array}$ \\
\hline LY4997 & - & 19.3 & 11.1 & 11.2 \\
LY5034 v01 & 14 & 18.1 & 8.0 & 7.1 \\
LY5003 v01 & 103 & $10.2+$ & 7.8 & 5.7 \\
LY4248 v01 & 298 & 20 & 9.0 & 4.9 \\
LY5004 v01 & 569 & $9.1+$ & 9.3 & 4.5 \\
LY5061 s01 & 660 & 3.3 & 11.1 & 3.6 \\
LY4393 v01 & 829 & 5.8 & 5.0 & 4.6 \\
\hline
\end{tabular}

\subsection{Aquifer analysis}

The pre-test monitoring shows the potentiometric surface of the M1B aquifer dips to the west in response to the presence of the mine void. Given this aquifer is not actively pumped as it is not significant to the current mine footprint, this indicates that lowering of the aquifer pressures is occurring via drainage from the active mine face. Recent observations in the mine face have confirmed this.

Aquifer analysis was undertaken using AQTESOLV Pro software, incorporating the following parameters:

- Confined aquifer, fully penetrating (for pumping bore).

- Observation bores were listed as partially penetrating.

- Introduction of a barrier boundary approximately $950 \mathrm{~m}$ west of LY4997 based on the isopachs and lithological data for the aquifer and supported by diagnostic plots showing a doubling of the slope of drawdown with increased pumping duration.

A range of solutions were applied, and the Theis/Hantush method was considered to provide the best match of drawdown and derivative data.

Transmissivity and storativity results from the pumping test analysis are summarised in Table 3. 
Table 3 Pumping test analysis summary results

\begin{tabular}{lllll}
\hline $\begin{array}{l}\text { Matched } \\
\text { bore }\end{array}$ & Solution method & $\begin{array}{l}\text { Aquifer } \\
\text { model }\end{array}$ & $\begin{array}{l}\text { Transmissivity } \\
\left(\mathbf{m}^{2} / \text { day }\right)\end{array}$ & $\begin{array}{l}\text { Storativity } \\
(-)\end{array}$ \\
\hline LY4997 & Theis/Hantush & Confined & 533 & - \\
LY5034 & Theis/Hantush & Confined & 427 & $1.3 \mathrm{E}-4$ \\
LY5003 & Theis/Hantush & Confined & 451 & $7.9 \mathrm{E}-5$ \\
LY4248 & Theis/Hantush & Confined & 443 & $4.9 \mathrm{E}-5$ \\
LY5061 & Theis/Hantush & Confined & 325 & $1.2 \mathrm{E}-4$ \\
LY5004 & Theis/Hantush & Confined & 308 & $1.2 \mathrm{E}-4$ \\
LY4393 & Theis/Hantush & Confined & 300 & $1.1 \mathrm{E}-4$ \\
Geometric & mean & & 370 & $1.0 \mathrm{E}-4$ \\
All & Theis/Hantush & Confined & 531 & $1.9 \mathrm{E}-5$ \\
All & Distance drawdown & Confined & 509 & $2.3 \mathrm{E}-5$ \\
\hline
\end{tabular}

Note: all analyses assumed that a lineal no-flow boundary was present to the west of pumping bore LY4997. The boundary was defined by mine co-ordinates $(418,650,261,000$ and $417,550,264,000)$, which lies approximately $930 \mathrm{~m}$ to the west.

The results of the distance drawdown and composite analysis are considered the most representative of the bulk aquifer parameters and, therefore, with an aquifer transmissivity of around $500 \mathrm{~m}^{2} /$ day and an aquifer thickness of around $20 \mathrm{~m}$ at the pump bores, the hydraulic conductivity is estimated at $25 \mathrm{~m} /$ day. The range of representative hydraulic conductivity values for a medium sand is reported at 0.1 to $40 \mathrm{~m} /$ day (Duffield 2008) and the results from bore LY4997 of $25 \mathrm{~m} /$ day are consistent with the thick medium sand as described in the geological logs.

\subsection{Groundwater sampling results}

The field water quality monitoring indicated that the temperature marginally increased during the seven day test from around 37.5 to $39.5^{\circ} \mathrm{C}$ and $\mathrm{pH}$ and electrical conductivity were relatively stable with respective average values of $\mathrm{pH} 5.4$ and $580 \mathrm{\mu S} / \mathrm{cm}$.

Laboratory analytical results indicate that the groundwater quality comprises low salinity at $226 \mathrm{mg} / \mathrm{L}$ total dissolved solids with $\mathrm{Na}$ and $\mathrm{Cl}$ the dominant ions, and is slightly acidic with a median $\mathrm{pH}$ of 5.4. Elevated iron concentrations were recorded at $2.1 \mathrm{mg} / \mathrm{L}$ as is typical for this aquifer and evident during the pumping test.

Based on this salinity, the M1B aquifer groundwater falls within Segment A1 as classified by the State Environment Protection Policy (Government of Victoria 2018). Segment A1 groundwater has a wide range of potential beneficial uses; however, it is noted that some beneficial uses are unlikely to be realised at the mine site.

\section{$5 \quad$ Groundwater management options}

The dewatering activities will generate water that is required to be managed. Currently all pumped groundwater is collected and used in the power station. If AGL were to pursue alternative disposal options, the management of future M1B abstractions would need to be consistent with the Environmental Protection Authority's waste management hierarchy, in which avoidance is the highest priority, and disposal, the lowest. The likely outcome will be based on providing the highest practical beneficial use. Based on the high level review of the potential water management options, and the aquifer's remoteness from current pipeline infrastructure, it is understood that discharge to nearby Sheepwash Creek of some or all of the M1B groundwater is currently the preferred method for managing the abstracted groundwater as it potentially becomes available to 
downstream users. A number of regulatory requirements will need to be met in order to obtain approval for discharge of groundwater to the creek, and these are currently being investigated by AGL.

\section{Mine depressurisation requirements and mine plan constraints}

The proposed mine plans to 2048 show that the aquifer will be present at a thickness of between 2 and $20 \mathrm{~m}$ in the future mine footprint. A change of mine grade (or 'step up' of the mine floor) approximately coincides with the significant thickening of the overlying M1A aquifer. The M1B aquifer will be exposed in the batter face created at the step up (and excavated west of this point), which presents geotechnical challenges for managing batter stability, especially as the aquifer is expected to naturally dewater into the pit (and potentially wash out). Further east, the M1B interseam (including the M1B aquifer) will be present at shallow depths below the mine floor. Proposed mine plans show the change of grade will occur in approximately 10 years.

The M1B aquifer will be present below the overlying thin M1B coal and interseam clay or will be exposed in increasingly larger areas of the mine floor depending on the final mine grades from approximately 2026 to 2035 when the base of mine reaches its eastern margin.

AGL Loy Yang maintains a mine-scale groundwater model within the regional Latrobe Valley using MODFLOW unstructured grids, and the results of this aquifer assessment will be included in future updates of the model. The strategy to manage future M1B aquifer flows is to install a pumping bore network on permanent batters effectively acting to intercept flows onto the mine. The proposed pumping bore network should be complete by 2028 -the locations of which are shown in Figure 5 . The planned pump bores target the exposures of the M1B aquifer in the northeast of the mine from the 2024 mine plan, and in the step up in the mine floor from 2026. Groundwater extraction licence modifications have been obtained from Southern Rural Water to allow pumping from the M1B aquifer from 2020.

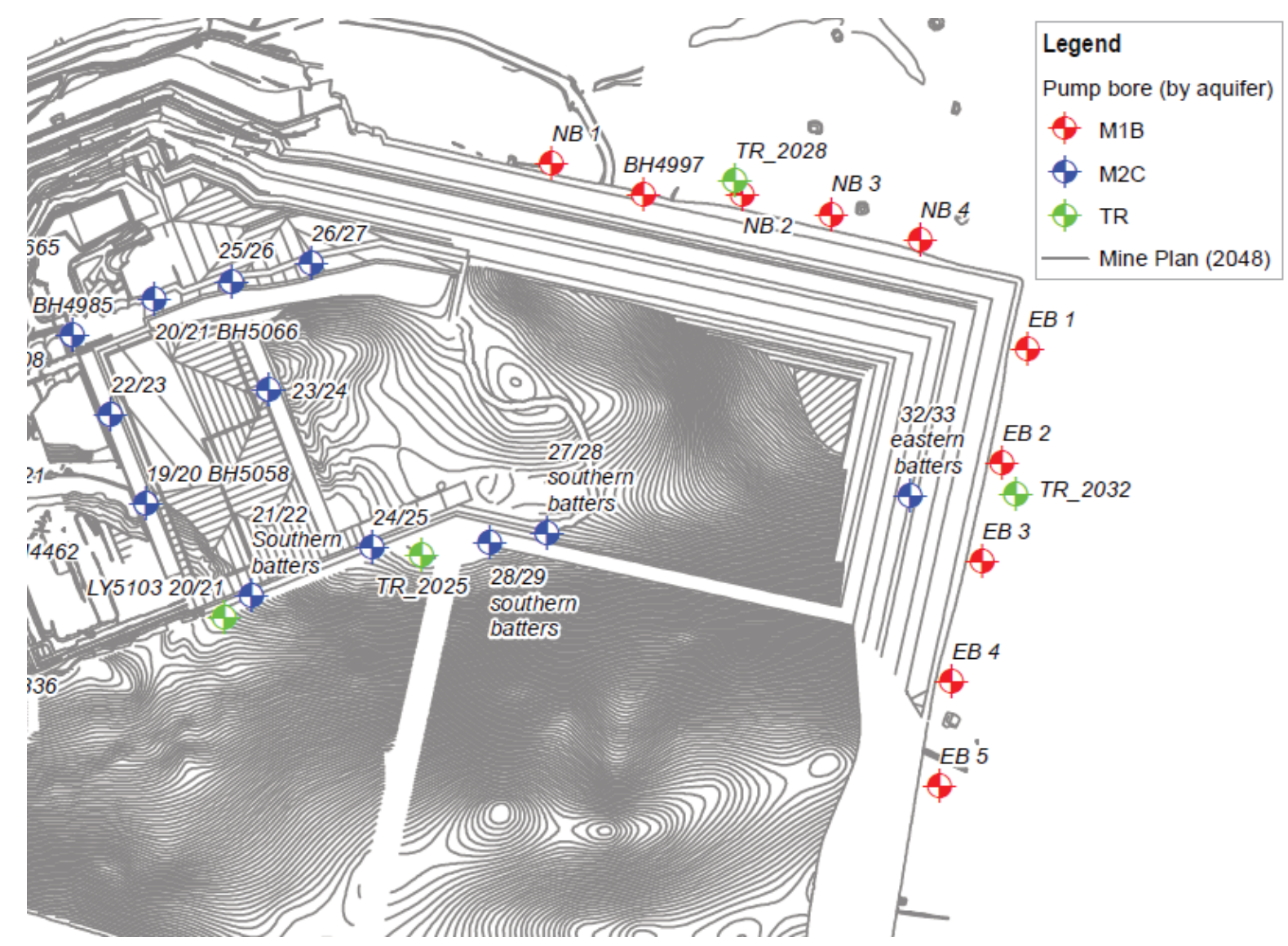

Figure 5 Proposed M1B aquifer pumping network. Note: M2C and TR represent deeper lithological units (including aquifers) which are actively depressurised beneath the current mine footprint 
Recent groundwater modelling of the M1B aquifer has shown that in the longer term, the elevation (and hydraulic gradient) of the M1B aquifer in the base of mine dips towards the east, which is subsequently mirrored by the proposed mine floor design. As such, seepage volumes from the M1B aquifer should decrease over time as pressures lower and the aquifer begins to drain towards the east. Localised dewatering contingency measures may be required prior to and during the excavation of the permanent step up batter (within the mine) and could include horizontal drains and localised relief wells and/or in-pit pumping bores.

\section{Conclusion}

The conclusion of the pumping test confirms the M1B aquifer is regionally confined and of moderate to high transmissivity. The pumping test returned a transmissivity value around $500 \mathrm{~m}^{2} /$ day and storativity values between $1.3 \times 10^{-4}$ to $1.9 \times 10^{-5}$.

Tests indicated the aquifer is well-connected over the future mining area, and that a network of pumping bores should be gradually commissioned between 2020 and 2028 to facilitate depressurisation of the aquifer ahead of mining. Natural localised dewatering is expected to occur as the aquifer is intercepted by batter configurations, and batter stability considerations will need to be managed as mining progresses towards the east.

\section{Acknowledgement}

The authors thank AGL for their support and assistance with undertaking this project, and Tim Anderson, hydrogeologist from GHD, who provided assistance and oversight with pumping test analysis.

\section{References}

Duffield, GM 2008, AQTESOLV Aquifer Test Analysis Short Course, November 2008.

GHD Group Pty Ltd 2015, Geology of Loy Yang Mine, August 2015, AGL Loy Yang, Traralgon.

Government of Victoria 2018, State Environment Protection Policy (Waters). 
